\title{
Supplier Selection Group Decision Making in Logistics Service Value Cocreation Based on Intuitionistic Fuzzy Sets
}

\author{
Qifeng Wang and Hongbo Lv \\ Modern Logistics School, Zhejiang Wanli University, Ningbo 315100, China \\ Correspondence should be addressed to Qifeng Wang; lhywqf@163.com
}

Received 8 May 2015; Revised 29 June 2015; Accepted 1 July 2015

Academic Editor: Juan R. Torregrosa

Copyright (C) 2015 Q. Wang and H. Lv. This is an open access article distributed under the Creative Commons Attribution License, which permits unrestricted use, distribution, and reproduction in any medium, provided the original work is properly cited.

\begin{abstract}
Intuitionistic fuzzy information aggregation plays an important role in intuitionistic fuzzy set theory and is widely used in group decision making. In this paper, an induced intuitionistic fuzzy Einstein hybrid aggregation operator (I-IFEHA) is investigated for supplier selection group decision making in logistics service value cocreation based on fuzzy measures. We first introduce some aggregation operators and Einstein operations on intuitionistic fuzzy sets and develop a new induced intuitionistic fuzzy Einstein hybrid aggregation operator to accommodate the environment in which the given arguments are intuitionistic fuzzy values. Then, we study the supplier selection group decision model in logistics service value cocreation based on intuitionistic fuzzy sets with the I-IFEHA operator. Finally, an example of 3PL supplier selection in logistics service value cocreation environment is given to verify the developed approach and to demonstrate the effectiveness of the developed approach.
\end{abstract}

\section{Introduction}

In today's business world, more and more companies rely on outsourcing their logistics services to 3PL to reduce costs, improve business performance, and focus on their core business. Supplier selection has received considerable attention for its significant effect towards successful logistics and supply chain management [1]. The 3PL supplier selection issue is a typical multiple attribute decision making problem in complex business environment. The study of 3PL supplier selection mainly includes the following two main issues; one is the selection criteria of 3PL supplier [2-7] and the other is the selection models and approaches of 3PL supplier [8-16]. In many decision making scenarios, most decision information provided by the decision maker is often imprecise or uncertain due to the complex decision making environment, lack of data, or the decision maker's limited knowledge. The accuracy of 3PL supplier selection decision making process is based on the correct information from fuzzy data. To calculate the fuzzy data, Atanassov introduced the concept of intuitionistic fuzzy set (IFS) characterized by a membership function and nonmembership function, which is more suitable for dealing with fuzziness and uncertainty than the ordinary fuzzy set developed by Atanassov et al. [1720]. Since its appearance, IFS has received more and more attention in the field of multiple attribute decision making [20-35]. Xu [36] developed the intuitionistic fuzzy weighted averaging (IFWA) operator, the intuitionistic fuzzy ordered weighted averaging (IFOWA) operator, and the intuitionistic fuzzy hybrid aggregation (IFHA) operator. Xu and Yager [37] proposed some intuitionistic fuzzy geometric aggregation operators and applied them to multiattribute decision making problems. Merigó [38] presented a new operator that unifies the OWA operator with the WA when we assess the information with induced aggregation operators called the induced ordered weighted averaging-weighted average (IOWAWA) operator. Wei [39] proposed the dynamic intuitionistic fuzzy weighted geometric (DIFWG) and induced intuitionistic fuzzy ordered weighted geometric (I-IFOWG) operator [40]. Xu and Wang [41] developed the induced generalized intuitionistic fuzzy ordered weighted averaging (I-GIFOWA) operator.

It is clear that the above operators are based on the algebraic operational laws of IFSs for carrying the combination process and are not consistent with the limiting case of ordinary fuzzy sets [20]. For an intersection, a good alternative 
to the algebraic operational laws is Einstein operation laws for fuzzy sets. Wang and Liu [42, 43] developed intuitionistic fuzzy aggregation operators based on Einstein operators. Zhao and Wei [20] developed the intuitionistic fuzzy Einstein hybrid averaging (IFEHA) operator and intuitionistic fuzzy Einstein hybrid geometric (IFEHG) operator and applied the intuitionistic fuzzy Einstein hybrid averaging (IFEHA) operator and intuitionistic fuzzy Einstein hybrid geometric (IFEHG) operator to deal with multiple attribute decision making under intuitionistic fuzzy environments. Xu et al. [44] developed an I-IFOWA ${ }^{\varepsilon}$ operator which generalizes some of the intuitionistic fuzzy Einstein aggregation operators and apply the I-IFOWA ${ }^{\varepsilon}$ operator and the $\mathrm{IFWA}^{\varepsilon}$ operator to multiple attribute group decision making with intuitionistic fuzzy information. Yet it is worthy of pointing out that there is little investigation on aggregation technologies using the Einstein operations on IFS and the induced intuitionistic fuzzy aggregation operator is more suitable for aggregation individual intuitionistic fuzzy values into collective intuitionistic fuzzy value. Therefore, this paper focuses on developing an induced intuitionistic fuzzy aggregation operator based on Einstein operators considering both the weights of positions and attributes.

In order to do so, the remainder of the paper is organized as follows. Section 2 briefly introduces some basic concepts related to intuitionistic fuzzy sets and some existing intuitionistic fuzzy aggregating operators. In Section 3, based on the induction of Einstein operation laws, we develop an induced intuitionistic fuzzy Einstein hybrid aggregation operator (I-IFEHA) and study some desired properties of the operator. In Section 4, we study the supplier selection group decision model in logistics service value cocreation and apply I-IFEHA operator to deal with supplier selection group decision making problems. In Section 5, an illustrative example for 3PL supplier selection in logistics service value cocreation environment is given to illustrate the concrete application of the approach. Section 6 concludes the paper and gives some remarks.

\section{Preliminaries}

In the following, we will first briefly introduce some basic concepts, aggregation operators related to intuitionistic fuzzy sets (IFSs) to facilitate future discussions.

2.1. Intuitionistic Fuzzy Set. Intuitionistic fuzzy set (IFS) introduced by Atanassov [17] is an extension of the classical fuzzy set, which is a suitable way to deal with vagueness. It can be defined as follows.

Definition 1. Let $X$ be a universe of discourse. An IFS in $X$ is given by

$$
A=\left\{\left\langle x, \mu_{A}(x), \nu_{A}(x)\right\rangle \mid x \in X\right\},
$$

where $\mu_{A}(x), v_{A}(x) \in[0,1]$, with the condition $0 \leq \mu_{A}(x)+$ $v_{A}(x) \leq 1, \forall x \in X$. The numbers $\mu_{A}(x)$ and $v_{A}(x)$ represent, respectively, the degree of membership and the degree of nonmembership of the element $x$ to the set $A[17,18]$.
Definition 2. For each IFS $A$ in $X$, if

$$
\pi_{A}(x)=1-\mu_{A}(x)-v_{A}(x), \quad \forall x \in X,
$$

then $\pi_{A}(x)$ is called the indeterminacy degree of $x$ to set $A$ $[17,18]$.

For computational convenience, the pair $\left(\mu_{A}(x), v_{A}(x)\right)$ is called an intuitionistic fuzzy value (IFV) [31], which is simply denoted as $\alpha=\left(\mu_{A}, v_{A}\right)$ such that $\mu_{A}(x), v_{A}(x) \in[0,1]$ and $0 \leq \mu_{A}(x)+\nu_{A}(x) \leq 1$.

Definition 3. Let $\alpha=\left(\mu_{\alpha}, \nu_{\alpha}\right)$ be an IFV; a score function $S$ of an intuitionistic fuzzy value can be represented as follows [21]:

$$
S(\alpha)=\mu_{\alpha}-v_{\alpha}, \quad \text { where } S(\alpha) \in[-1,1] .
$$

The function $S$ is used to measure the score of an IFV. The bigger the score of $\alpha$, the larger the IFV $\alpha$.

Definition 4. Let $\alpha=\left(\mu_{\alpha}, \nu_{\alpha}\right)$ be an IFV; an accuracy function $H$ of an intuitionistic fuzzy value can be represented as follows [22]:

$$
H(\alpha)=\mu_{\alpha}+v_{\alpha}, \quad \text { where } H(\alpha) \in[0,1] .
$$

The function $H$ is used to evaluate the accuracy of an IFV. The larger the value of $H(\alpha)$, the higher the degree of accuracy of the IFV $\alpha$.

Definition 5 (see [37]). Let $\alpha=\left(\mu_{\alpha}, v_{\alpha}\right)$ and $\beta=\left(\mu_{\beta}, v_{\beta}\right)$ be two IFVs, let $S(\alpha)=\mu_{\alpha}-v_{\alpha}$ and $S(\beta)=\mu_{\beta}-v_{\beta}$ be the score of $\alpha$ and $\beta$, respectively, and let $H(\alpha)=\mu_{\alpha}+\nu_{\alpha}$ and $H(\beta)=\mu_{\beta}+\nu_{\beta}$ be the accuracy degree of $\alpha$ and $\beta$, respectively; then one gets the following:

(1) If $S(\alpha)<S(\beta)$, then $\alpha<\beta$.

(2) If $S(\alpha)=S(\beta)$, then one gets the following:

(a) If $H(\alpha)<H(\beta)$, then $\alpha<\beta$.

(b) If $H(\alpha)=H(\beta)$, then $\alpha=\beta$.

2.2. The Intuitionistic Fuzzy Aggregation Operator. Intuitionistic fuzzy information aggregation plays an important role in intuitionistic fuzzy set theory. $\mathrm{Xu}$ [36] proposed some intuitionistic fuzzy aggregation operators to aggregate the intuitionistic fuzzy information.

Definition 6 (see [36]). Let $\alpha_{j}=\left(\mu_{j}, \nu_{j}\right)(j=1,2, \ldots, n)$ be a collection of IFVs and an intuitionistic fuzzy weighted averaging operator of dimension $n$ is a mapping IFWA: $\Omega^{n} \rightarrow \Omega$, if

$$
\begin{aligned}
& \operatorname{IFWA}_{w}\left(\alpha_{1}, \alpha_{2}, \ldots, \alpha_{n}\right)=\sum_{j=1}^{n} w_{j} \alpha_{j} \\
& =\left(1-\prod_{j=1}^{n}\left(1-\mu_{j}\right)^{w_{j}}, \prod_{j=1}^{n}\left(v_{j}\right)^{w_{j}}\right),
\end{aligned}
$$

where $w=\left(w_{1}, w_{2}, \ldots, w_{n}\right)^{T}$ is the weighting vector of $\alpha_{j}(j=1,2, \ldots, n)$ with $w_{j} \in[0,1], \sum_{j=1}^{n} w_{j}=1$. 
Definition 7 (see [36]). Let $\alpha_{j}=\left(\mu_{j}, \nu_{j}\right)(j=1,2, \ldots, n)$ be a collection of IFVs and an intuitionistic fuzzy ordered weighted averaging operator of dimension $n$ is a mapping IFOWA: $\Omega^{n} \rightarrow \Omega$, if

$$
\begin{aligned}
& \operatorname{IFOWA}_{w}\left(\alpha_{1}, \alpha_{2}, \ldots, \alpha_{n}\right)=\sum_{j=1}^{n} w_{j} \alpha_{\sigma(j)} \\
& =\left(1-\prod_{j=1}^{n}\left(1-\mu_{\sigma(j)}\right)^{w_{j}}, \prod_{j=1}^{n}\left(v_{\sigma(j)}\right)^{w_{j}}\right),
\end{aligned}
$$

where $\alpha_{\sigma(j)}$ is $j$ th largest of $\alpha_{j}(j=1,2, \ldots, n)$ and $w=$ $\left(w_{1}, w_{2}, \ldots, w_{n}\right)^{T}$ is the aggregation-associated weighting vector with $w_{j} \in[0,1], \sum_{j=1}^{n} w_{j}=1$.

The intuitionistic fuzzy hybrid aggregation operator (IFHA) was introduced by $\mathrm{Xu}$ [36]. It is an extension of the IFWA operator and IFOWA operator for uncertain situations where the available information can be assessed with IFVs. Let $\Omega$ be the set of all IFVs; it can be defined as follows.

Definition 8. Let $\alpha_{j}=\left(\mu_{j}, \nu_{j}\right)(j=1,2, \ldots, n)$ be a collection of IFVs and an intuitionistic fuzzy hybrid aggregation operator of dimension $n$ is a mapping IFHA: $\Omega^{n} \rightarrow \Omega$, if

$$
\begin{aligned}
& \operatorname{IFHA}_{w, \omega}\left(\alpha_{1}, \alpha_{2}, \ldots, \alpha_{n}\right)=\sum_{j=1}^{n} w_{j} \dot{\alpha}_{\sigma(j)} \\
& \quad=\left(1-\prod_{j=1}^{n}\left(1-\dot{\mu}_{\sigma(j)}\right)^{w_{j}}, \prod_{j=1}^{n}\left(\dot{v}_{\sigma(j)}\right)^{w_{j}}\right),
\end{aligned}
$$

where $\dot{\alpha}_{\sigma(j)}$ is $j$ th largest of the weighted intuitionistic fuzzy values $\dot{\alpha}_{j}\left(\dot{\alpha}_{j}=n \omega_{j} \alpha_{j}, j=1,2, \ldots, n\right), \omega=\left(\omega_{1}, \omega_{2}, \ldots, \omega_{n}\right)^{T}$ is the weighting vector of $\alpha_{j}(j=1,2, \ldots, n)$ with $\omega_{j} \geq$ $0, \sum_{j=1}^{n} \omega_{j}=1$, and $n$ is the balancing coefficient. $w=$ $\left(w_{1}, w_{2}, \ldots, w_{n}\right)^{T}$ is the aggregation-associated weighting vector with $w_{j} \in[0,1], \sum_{j=1}^{n} w_{j}=1$.

The induced intuitionistic fuzzy hybrid aggregation operator (I-IFHA) is the extension of the IFHA operator. The main difference is that the reordering step in I-IFHA is not carried out with the values of the argument $\dot{\alpha}_{j}$. In this case, the reordering step is developed with order-inducing variables that reflect a more complex reordering process.

Definition 9 (see [45]). An I-IFHA operator of dimension $n$ is a mapping I-IFHA: $\Omega^{n} \rightarrow \Omega$, if

$$
\begin{aligned}
& \operatorname{I-IFHA~}_{w, \omega}\left(\left\langle u_{1}, \alpha_{1}\right\rangle,\left\langle u_{2}, \alpha_{2}\right\rangle, \ldots,\left\langle u_{n}, \alpha_{n}\right\rangle\right) \\
& =\sum_{j=1}^{n} w_{j} \dot{\alpha}_{\sigma(j)} \\
& =\left(1-\prod_{j=1}^{n}\left(1-\dot{\mu}_{\sigma(j)}\right)^{w_{j}}, \prod_{j=1}^{n}\left(\dot{v}_{\sigma(j)}\right)^{w_{j}}\right),
\end{aligned}
$$

where $w=\left(w_{1}, w_{2}, \ldots, w_{n}\right)^{T}$ is the aggregation-associated weighting vector such that $w_{j} \in[0,1], \sum_{j=1}^{n} w_{j}=1 . \dot{\alpha}_{\sigma(j)}$ is $\dot{\alpha}_{j}\left(\dot{\alpha}_{j}=n \omega_{j} \alpha_{j}, j=1,2, \ldots, n\right)$ value of the pair $\left\langle u_{j}, \dot{\alpha}_{j}\right\rangle$ having $j$ th largest $u_{j}$ which is the order-inducing variable and $\dot{\alpha}_{j}$ is the argument variable, and $\omega=\left(\omega_{1}, \omega_{2}, \ldots, \omega_{n}\right)^{T}$ is the weighting vector of $\alpha_{j}(j=1,2, \ldots, n)$ with $\omega_{j} \geq$ $0, \sum_{j=1}^{n} \omega_{j}=1$, and $n$ is the balancing coefficient.

\section{The Induced Intuitionistic Fuzzy Einstein Hybrid Aggregation Operator}

Besides the algebra operations for IFVs, there are various $t$-norms and $t$-conorms can satisfy the requirements of the conjunction and disjunction operators. Einstein operations include the Einstein product which is a $t$-norm and Einstein sum which is $t$-conorms can be used to perform the corresponding intersections and unions of IFVs. Wang and Liu [42] extended the Einstein operations to the IFVs. Let $A$ and $B$ be two IFSs; then the Einstein operators are as follows:

(1)

$$
\begin{aligned}
A \bigoplus_{\varepsilon} B= & \left\{\left\langlex, \frac{\mu_{A}(x)+\mu_{B}(x)}{1+\mu_{A}(x) \cdot \mu_{B}(x)},\right.\right. \\
& \left.\left.\frac{v_{A}(x) \cdot v_{B}(x)}{1+\left(1-v_{A}(x)\right) \cdot\left(1-\nu_{B}(x)\right)}\right\rangle \mid x \in X\right\} .
\end{aligned}
$$

(2)

$$
\begin{aligned}
& A \bigotimes_{\varepsilon} B=\left\{\left\langlex, \frac{\mu_{A}(x) \cdot \mu_{B}(x)}{1+\left(1-\mu_{A}(x)\right) \cdot\left(1-\mu_{B}(x)\right)},\right.\right. \\
& \left.\left.\quad \frac{v_{A}(x)+v_{B}(x)}{1+v_{A}(x) \cdot v_{B}(x)}\right\rangle \mid x \in X\right\} .
\end{aligned}
$$

(3)

$$
\begin{aligned}
A^{\wedge_{\varepsilon}} \lambda & =\left\{\left\langlex, \frac{2\left(\mu_{A}(x)\right)^{\lambda}}{\left(2-\mu_{A}(x)\right)^{\lambda}+\left(\mu_{A}(x)\right)^{\lambda}},\right.\right. \\
& \left.\left.\frac{\left(1+v_{A}(x)\right)^{\lambda}-\left(1-v_{A}(x)\right)^{\lambda}}{\left(1+v_{A}(x)\right)^{\lambda}+\left(1-v_{A}(x)\right)^{\lambda}}\right\rangle \mid x \in X\right\} .
\end{aligned}
$$

(4)

$$
\begin{gathered}
\lambda_{\varepsilon} A=\left\{\left\langlex, \frac{\left(1+\mu_{A}(x)\right)^{\lambda}-\left(1-\mu_{A}(x)\right)^{\lambda}}{\left(1+\mu_{A}(x)\right)^{\lambda}+\left(1-\mu_{A}(x)\right)^{\lambda}},\right.\right. \\
\left.\left.\frac{2\left(v_{A}(x)\right)^{\lambda}}{\left(2-v_{A}(x)\right)^{\lambda}+\left(\nu_{A}(x)\right)^{\lambda}}\right\rangle \mid x \in X\right\} .
\end{gathered}
$$

Based upon the definition of Einstein operations for IFVs and intuitionistic fuzzy aggregation operator proposed by $\mathrm{Xu}$ [36], Wang and Liu [42] proposed the intuitionistic fuzzy Einstein weighted averaging operator (IFEWA) and intuitionistic fuzzy Einstein ordered weighted averaging operator (IFEOWA). 
Definition 10 (see [42]). Let $\alpha_{j}=\left(\mu_{j}, v_{j}\right)(j=1,2, \ldots, n)$ be a collection of IFVs and an intuitionistic fuzzy Einstein weighted averaging operator of dimension $n$ is a mapping IFEWA: $\Omega^{n} \rightarrow \Omega$, if

$$
\begin{aligned}
& \operatorname{IFEWA}_{w}\left(\alpha_{1}, \alpha_{2}, \ldots, \alpha_{n}\right) \\
& =\left(\frac{\prod_{j=1}^{n}\left(1+\mu_{j}\right)^{w_{j}}-\prod_{j=1}^{n}\left(1-\mu_{j}\right)^{w_{j}}}{\prod_{j=1}^{n}\left(1+\mu_{j}\right)^{w_{j}}+\prod_{j=1}^{n}\left(1-\mu_{j}\right)^{w_{j}}},\right. \\
& \left.\frac{2 \prod_{j=1}^{n}\left(v_{j}\right)^{w_{j}}}{\prod_{j=1}^{n}\left(2-v_{j}\right)^{w_{j}}+\prod_{j=1}^{n}\left(v_{j}\right)^{w_{j}}}\right),
\end{aligned}
$$

where $w=\left(w_{1}, w_{2}, \ldots, w_{n}\right)^{T}$ is the weighting vector of $\alpha_{j}(j=1,2, \ldots, n)$ with $w_{j} \in[0,1], \sum_{j=1}^{n} w_{j}=1$.

Based on the OWA operator and the IFEWA operator, an IFEOWA operator is defined as follows.

Definition 11 (see [42]). Let $\alpha_{j}=\left(\mu_{j}, v_{j}\right)(j=1,2, \ldots, n)$ be a collection of IFVs and an intuitionistic fuzzy Einstein ordered weighted averaging operator of dimension $n$ is a mapping IFEOWA: $\Omega^{n} \rightarrow \Omega$, if

$$
\begin{aligned}
& \operatorname{IFEOWA}_{w}\left(\alpha_{1}, \alpha_{2}, \ldots, \alpha_{n}\right) \\
& =\left(\frac{\prod_{j=1}^{n}\left(1+\mu_{\sigma(j)}\right)^{w_{j}}-\prod_{j=1}^{n}\left(1-\mu_{\sigma(j)}\right)^{w_{j}}}{\prod_{j=1}^{n}\left(1+\mu_{\sigma(j)}\right)^{w_{j}}+\prod_{j=1}^{n}\left(1-\mu_{\sigma(j)}\right)^{w_{j}}},\right. \\
& \left.\frac{2 \prod_{j=1}^{n}\left(v_{\sigma(j)}\right)^{w_{j}}}{\prod_{j=1}^{n}\left(2-v_{\sigma(j)}\right)^{w_{j}}+\prod_{j=1}^{n}\left(v_{\sigma(j)}\right)^{w_{j}}}\right),
\end{aligned}
$$

where $\alpha_{\sigma(j)}$ is $j$ th largest of $\alpha_{j}(j=1,2, \ldots, n)$ and $w=$ $\left(w_{1}, w_{2}, \ldots, w_{n}\right)^{T}$ is the aggregation-associated weighting vector with $w_{j} \in[0,1], \sum_{j=1}^{n} w_{j}=1$.

From Definitions 10 and 11, we know that the IFEWA operator weights only represent the intuitionistic fuzzy values, while the IFWOWA operator weights only represent the ordered positions of the intuitionistic fuzzy values. To solve this drawback and reflect the importance degrees of both given arguments and their ordered positions, Zhao and Wei [20] proposed an intuitionistic fuzzy Einstein hybrid aggregation operator (IFEHA), which is defined as follows.

Definition 12 (see [20]). An IFEHA operator of dimension $n$ is a mapping IFEHA: $\Omega^{n} \rightarrow \Omega$, if

$$
\begin{aligned}
& \operatorname{IFEHA}_{w, \omega}\left(\alpha_{1}, \alpha_{2}, \ldots, \alpha_{n}\right)=\bigoplus_{j=1}^{n} w_{j} \dot{\alpha}_{\sigma(j)} \\
& =\left(\frac{\prod_{j=1}^{n}\left(1+\dot{\mu}_{\sigma(j)}\right)^{w_{j}}-\prod_{j=1}^{n}\left(1-\dot{\mu}_{\sigma(j)}\right)^{w_{j}}}{\prod_{j=1}^{n}\left(1+\dot{\mu}_{\sigma(j)}\right)^{w_{j}}+\prod_{j=1}^{n}\left(1-\dot{\mu}_{\sigma(j)}\right)^{w_{j}}},\right. \\
& \left.\frac{2 \prod_{j=1}^{n}\left(\dot{v}_{\sigma(j)}\right)^{w_{j}}}{\prod_{j=1}^{n}\left(2-\dot{v}_{\sigma(j)}\right)^{w_{j}}+\prod_{j=1}^{n}\left(\dot{v}_{\sigma(j)}\right)^{w_{j}}}\right),
\end{aligned}
$$

where $\dot{\alpha}_{\sigma(j)}$ is $j$ th largest of the weighted intuitionistic fuzzy values $\dot{\alpha}_{j}\left(\dot{\alpha}_{j}=n \omega_{j} \alpha_{j}, j=1,2, \ldots, n\right), \omega=\left(\omega_{1}, \omega_{2}, \ldots, \omega_{n}\right)^{T}$ is the weighting vector of $\alpha_{j}(j=1,2, \ldots, n)$ with $\omega_{j} \geq$ $0, \sum_{j=1}^{n} \omega_{j}=1$, and $n$ is the balancing coefficient. $w=$ $\left(w_{1}, w_{2}, \ldots, w_{n}\right)^{T}$ is the aggregation-associated weighting vector with $w_{j} \in[0,1], \sum_{j=1}^{n} w_{j}=1$.

Based on the idea of IFEHA operator and I-IFHA operator, we develop the induced intuitionistic fuzzy Einstein hybrid aggregation operator as follows.

Definition 13. An I-IFEHA operator of dimension $n$ is a mapping I-IFEHA: $\Omega^{n} \rightarrow \Omega$, if

$$
\begin{aligned}
& \operatorname{I-IFEHA}_{w, \omega}\left(\left\langle u_{1}, \alpha_{1}\right\rangle,\left\langle u_{2}, \alpha_{2}\right\rangle, \ldots,\left\langle u_{n}, \alpha_{n}\right\rangle\right) \\
& =\bigoplus_{j=1}^{n} w_{j} \dot{\alpha}_{\sigma(j)} \\
& =\left(\frac{\prod_{j=1}^{n}\left(1+\dot{\mu}_{\sigma(j)}\right)^{w_{j}}-\prod_{j=1}^{n}\left(1-\dot{\mu}_{\sigma(j)}\right)^{w_{j}}}{\prod_{j=1}^{n}\left(1+\dot{\mu}_{\sigma(j)}\right)^{w_{j}}+\prod_{j=1}^{n}\left(1-\dot{\mu}_{\sigma(j)}\right)^{w_{j}}},\right. \\
& \left.\frac{2 \prod_{j=1}^{n}\left(\dot{v}_{\sigma(j)}\right)^{w_{j}}}{\prod_{j=1}^{n}\left(2-\dot{v}_{\sigma(j)}\right)^{w_{j}}+\prod_{j=1}^{n}\left(\dot{v}_{\sigma(j)}\right)^{w_{j}}}\right),
\end{aligned}
$$

where $w=\left(w_{1}, w_{2}, \ldots, w_{n}\right)^{T}$ is the aggregation-associated weighting vector such that $w_{j} \in[0,1], \sum_{j=1}^{n} w_{j}=1 . \dot{\alpha}_{\sigma(j)}$ is $\dot{\alpha}_{j}\left(\dot{\alpha}_{j}=n \omega_{j} \alpha_{j}, j=1,2, \ldots, n\right)$ value of the pair $\left\langle u_{j}, \dot{\alpha}_{j}\right\rangle$ having $j$ th largest $u_{j}$ which is the order-inducing variable and $\dot{\alpha}_{j}$ is the argument variable, and $\omega=\left(\omega_{1}, \omega_{2}, \ldots, \omega_{n}\right)^{T}$ is the weight vector of $\alpha_{j}(j=1,2, \ldots, n)$, with $\omega_{j} \geq 0, \sum_{j=1}^{n} \omega_{j}=$ 1 , and $n$ is the balancing coefficient.

Example 14. Assume the following collection of arguments with their respective order-inducing variables $\left\langle u_{j}, \alpha_{j}\right\rangle$ :

$$
\begin{aligned}
& \left\langle u_{1}, \alpha_{1}\right\rangle=\langle 0.2,(0.5,0.4)\rangle, \\
& \left\langle u_{2}, \alpha_{2}\right\rangle=\langle 0.4,(0.7,0.2)\rangle, \\
& \left\langle u_{3}, \alpha_{3}\right\rangle=\langle 0.6,(0.8,0.1)\rangle, \\
& \left\langle u_{4}, \alpha_{4}\right\rangle=\langle 0.3,(0.6,0.3)\rangle .
\end{aligned}
$$

We assume that the aggregation-associated weighting vector $w=(0.3,0.4,0.1,0.2)^{T}$ and the weight vector of $\alpha_{j}(j=$ $1,2,3,4), \omega=(0.3,0.4,0.2,0.1)^{T}$; then

$$
\begin{aligned}
& \left\langle\mu_{\sigma(1)}, \alpha_{\sigma(1)}\right\rangle=\langle 0.6,(0.706,0.173)\rangle, \\
& \left\langle\mu_{\sigma(2)}, \alpha_{\sigma(2)}\right\rangle=\langle 0.4,(0.883,0.058)\rangle, \\
& \left\langle\mu_{\sigma(3)}, \alpha_{\sigma(3)}\right\rangle=\langle 0.3,(0.270,0.666)\rangle, \\
& \left\langle\mu_{\sigma(4)}, \alpha_{\sigma(4)}\right\rangle=\langle 0.2,(0.578,0.319)\rangle .
\end{aligned}
$$


And then with (16) we can get the aggregated value:

$$
\begin{aligned}
& \operatorname{I-IFEHA}_{w, \omega}\left(\left\langle\mu_{1}, \alpha_{1}\right\rangle,\left\langle\mu_{2}, \alpha_{2}\right\rangle,\left\langle\mu_{3}, \alpha_{3}\right\rangle,\left\langle\mu_{4}, \alpha_{4}\right\rangle\right) \\
& \quad=(0.753,0.150) .
\end{aligned}
$$

I-IFEHA operator has the following properties, including commutativity, idempotency, boundedness, and monotonicity. Note that the proofs of these theorems are straightforward and thus are omitted.

Theorem 15 (commutativity). Let $\alpha_{j}=\left(\mu_{\alpha_{j}}, \nu_{\alpha_{j}}\right)(j=$ $1,2, \ldots, n)$ and $\alpha_{j}^{\prime}=\left(\mu_{\alpha_{j}^{\prime}}, \nu_{\alpha_{j}^{\prime}}\right)(j=1,2, \ldots, n)$ be two collections of IFVs; then

$$
\begin{aligned}
& I-I F E H A_{w, \omega}\left(\left\langle u_{1}, \alpha_{1}\right\rangle,\left\langle u_{2}, \alpha_{2}\right\rangle, \ldots,\left\langle u_{n}, \alpha_{n}\right\rangle\right) \\
& \quad=I-I F E H A_{w, \omega}\left(\left\langle u_{1}^{\prime}, \alpha_{1}^{\prime}\right\rangle,\left\langle u_{2}^{\prime}, \alpha_{2}^{\prime}\right\rangle, \ldots,\left\langle u_{n}^{\prime}, \alpha_{n}^{\prime}\right\rangle\right),
\end{aligned}
$$

where $\left(\left\langle u_{1}, \alpha_{1}\right\rangle,\left\langle u_{2}, \alpha_{2}\right\rangle, \ldots,\left\langle u_{n}, \alpha_{n}\right\rangle\right)$ is any permutation of $\left(\left\langle u_{1}^{\prime}, \alpha_{1}^{\prime}\right\rangle,\left\langle u_{2}^{\prime}, \alpha_{2}^{\prime}\right\rangle, \ldots,\left\langle u_{n}^{\prime}, \alpha_{n}^{\prime}\right\rangle\right)$.

Theorem 16 (idempotency). Let $\alpha_{j}=\left(\mu_{\alpha_{j}}, \nu_{\alpha_{j}}\right)(j=1,2, \ldots$, $n)$ be a collection of IFVs. If all $\alpha_{j}(j=1,2, \ldots, n)$ are equal, that is, $\alpha_{j}=\alpha$ for all $j$, then

$$
\operatorname{I-IFEHA} A_{w, \omega}\left(\left\langle u_{1}, \alpha_{1}\right\rangle,\left\langle u_{2}, \alpha_{2}\right\rangle, \ldots,\left\langle u_{n}, \alpha_{n}\right\rangle\right)=\alpha .
$$

Theorem 17 (boundedness). Let $\alpha_{j}=\left(\mu_{\alpha_{j}}, \nu_{\alpha_{j}}\right)(j=1,2, \ldots$, $n$ ) be a collection of IFVs and let $\alpha^{-}=\min _{j} \alpha_{j}, \alpha^{+}=\max _{j} \alpha_{j}$; then

$$
\begin{aligned}
\alpha^{-} & \leq I-I F E H A_{w, \omega}\left(\left\langle u_{1}, \alpha_{1}\right\rangle,\left\langle u_{2}, \alpha_{2}\right\rangle, \ldots,\left\langle u_{n}, \alpha_{n}\right\rangle\right) \\
& \leq \alpha^{+} .
\end{aligned}
$$

Theorem 18 (monotonicity). Let $\alpha_{j}=\left(\mu_{\alpha_{j}}, \nu_{\alpha_{j}}\right)(j=1,2, \ldots$, $n)$ and $\beta_{j}=\left(\mu_{\beta_{j}}, \nu_{\beta_{j}}\right)(j=1,2, \ldots, n)$ be two collections of IFVs; if $\alpha_{j} \leq \beta_{j}$ for all $j$, then

$$
\begin{aligned}
& \operatorname{I-IFEHA}_{w, \omega}\left(\left\langle u_{1}, \alpha_{1}\right\rangle,\left\langle u_{2}, \alpha_{2}\right\rangle, \ldots,\left\langle u_{n}, \alpha_{n}\right\rangle\right) \\
& \quad \leq I-I F E H A_{w, \omega}\left(\left\langle u_{1}, \beta_{1}\right\rangle,\left\langle u_{2}, \beta_{2}\right\rangle, \ldots,\left\langle u_{n}, \beta_{n}\right\rangle\right) .
\end{aligned}
$$

\section{Supplier Selection Group Decision Model in Logistics Service Value Cocreation Based on Intuitionistic Fuzzy Sets}

4.1. Supplier Selection Group Decision Model in Logistics Service Value Cocreation. Logistics supplier selection is a multicriteria problem and it requires taking into account a large number of attributes. Spencer et al. listed 23 potential selection attributes [2], and Govindan et al. identified 35 selection factors in their studies [9]. With the review of 67 3PL selection articles published within 1994-2013 period, Aicha revealed 11 key 3PL selection criteria, and each one is defined by a set of attributes; the study revealed cost was the widely adopted criteria, followed by relationship, service, and quality [7]. Although the abovementioned selection criteria are widely used in 3PL selection, the selection criteria are operational-oriented, while supply chain strategic and service value creation factors were seldom considered in logistics supplier selection in previous studies. It is necessary to reconsider the selection criteria in logistics service value cocreation scenario.

The creation of value is the core premise of establishing and maintaining the customer relationship and is the core purpose and central process of economic exchange [46]. In supply chain management environment, more and more companies realize the importance of logistics service value cocreation with partners. Logistics service value cocreation has become the new way for the 3PL to find an innovative mode to achieve competitive advantage and for the customers to achieve more customized product and service offerings [47]. The supplier selection is one of the most important issues for logistics service value cocreation in SCM environment. The emerging trend in 3PL supplier selection is the integration of traditional selection attributes, such as cost, response time, quality, and location, with the new factors in service value cocreation, such as new value creation, knowledge management, and service innovation. We integrate the traditional operational-oriented selection attributes and value cocreation oriented SCM strategic selection attributes to establish a comprehensive selection attributes for supplier selection in logistics service value cocreation scenario. The attributes of supplier selection in logistics service value cocreation are shown in Table 1.

4.2. An Approach to Supplier Selection Group Decision Making in Logistics Service Value Cocreation with Intuitionistic Fuzzy Information. In this section, we apply I-IFEHA operator and IFEWA operator to multiple attribute group decision making for supplier selection in logistics service value cocreation based on intuitionistic fuzzy information.

We suppose $A=\left\{A_{1}, A_{2}, \ldots, A_{n}\right\}$ is a discrete set of alternatives of logistics service provider and $P=$ $\left\{P_{1}, P_{2}, \ldots, P_{m}\right\}$ is a set of attributes, whose weight vector is $\omega=\left\{\omega_{1}, \omega_{2}, \ldots, \omega_{m}\right\}^{T}$, where $\omega_{j} \in[0,1], \sum_{j=1}^{m} \omega_{j}=1$. Let $D=\left\{D_{1}, D_{2}, \ldots, D_{k}\right\}$ be a set of decision makers (DMs) with the weight vector $u=\left\{u_{1}, u_{2}, \ldots, u_{k}\right\}^{T}$, where $u_{j} \in$ $[0,1], \sum_{j=1}^{k} u_{j}=1$. Suppose that $R^{(l)}=\left(r_{i j}^{(l)}\right)_{m \times n}$ is an intuitionistic fuzzy decision matrix, where $r_{i j}^{(l)}=\left(\mu_{i j}^{(l)}, v_{i j}^{(l)}\right)$ is an IFV provided by the DMs $D^{l} \in D$ for the alternative $A_{i} \in A$ with respect to the attribute $P_{j} \in P . \mu_{i j}^{(l)}$ indicates the degree that the alternative $A_{i}$ should satisfy the attribute $P_{j}$, and $v_{i j}^{(l)}$ indicates the degree that the alternative $A_{i}$ should not satisfy the attribute $P_{j}$, such that $\mu_{i j}^{(l)} \in[0,1], v_{i j}^{(l)} \in[0,1]$, and $\mu_{i j}^{(l)}+v_{i j}^{(l)} \leq 1$.

The method for solving the above logistics service value cocreation multiattribute group decision making problem with the intuitionistic fuzzy information involves the following steps. 
TABLE 1: The attributes of supplier selection in logistics service value cocreation.

\begin{tabular}{|c|c|c|}
\hline Attribute & Attribute elements & Attribute element description \\
\hline Value collaboration & $\begin{array}{l}\text { Strategic collaboration } \\
\text { Business objectives collaboration } \\
\text { Market collaboration }\end{array}$ & $\begin{array}{l}\text { Value collaboration is the basis of value cocreation, } \\
\text { which should be presented from the aspects of strategic, } \\
\text { business objective, and market. }\end{array}$ \\
\hline Knowledge matching & $\begin{array}{l}\text { Knowledge heterogeneous } \\
\text { Knowledge complementary } \\
\text { Knowledge creation } \\
\text { Knowledge transfer and sharing }\end{array}$ & $\begin{array}{l}\text { Knowledge plays an important role in logistics service } \\
\text { value cocreation; knowledge management is integrated } \\
\text { in the process of value cocreation. }\end{array}$ \\
\hline Service innovation ability & $\begin{array}{l}\text { Service concept innovation } \\
\text { Service process innovation } \\
\text { Service technology innovation } \\
\text { Service delivery mode } \\
\text { innovation }\end{array}$ & $\begin{array}{l}\text { Service innovation presents the abilities for the } 3 \mathrm{PL} \text { to } \\
\text { fulfill the service value cocreation in logistics service } \\
\text { solutions. }\end{array}$ \\
\hline Quality of service & $\begin{array}{l}\text { Response time } \\
\text { Service price } \\
\text { Service reliability } \\
\text { Logistics service network } \\
\text { Information sharing }\end{array}$ & $\begin{array}{l}\text { Quality of service is the traditional evaluation factors } \\
\text { for 3PL selection, which also presents the quality of } \\
\text { service value cocreation. }\end{array}$ \\
\hline Resource interaction & $\begin{array}{l}\text { Resource heterogeneous } \\
\text { Resource complementary } \\
\text { Resource dependency } \\
\text { Resource integration }\end{array}$ & $\begin{array}{l}\text { Logistics resource is the material basis for service value } \\
\text { cocreation. The logistics service is fulfilled with the } \\
\text { integration and interaction of different logistics } \\
\text { resource from the participated 3PLs. }\end{array}$ \\
\hline
\end{tabular}

Step 1. Choose the attributes for logistics supplier selection based on the logistics service value cocreation decision making model.

Step 2. Utilize the weighting vector $\omega=\left\{\omega_{1}, \omega_{2}, \ldots, \omega_{m}\right\}^{T}$ for the logistics supplier selection attribute and utilize the intuitionistic fuzzy decision matrix $R^{(k)}=\left(r_{i j}^{(k)}\right)_{m \times n}$ with weight vector $u=\left\{u_{1}, u_{2}, \ldots, u_{k}\right\}^{T}$ for decision makers.

Step 3. Utilize all the individual intuitionistic fuzzy decision matrices $R^{(l)}=\left(r_{i j}^{(l)}\right)_{m \times n}$ for logistics supplier selection into a collective intuitionistic fuzzy decision matrix $R=$ $\left(r_{i j}\right)_{m \times n}$ with the I-IFEHA operator which has the associated weighting vector $w=\left(w_{1}, w_{2}, \ldots, w_{k}\right)^{T}$ :

$$
\begin{aligned}
& r_{i j}=\operatorname{I-IFEHA}_{w, \omega}\left(\left\langle u_{1}, r_{i j}{ }^{(1)}\right\rangle,\left\langle u_{2}, r_{i j}{ }^{(2)}\right\rangle, \ldots,\right. \\
& \left.\quad\left\langle u_{k}, r_{i j}{ }^{(k)}\right\rangle\right) .
\end{aligned}
$$

Step 4. According to the collective intuitionistic fuzzy decision matrix $R=\left(r_{i j}\right)_{m \times n}$, then use the IFEWA operator to derive the overall intuitionistic fuzzy preference values $r_{i}$ of the alternative.

Step 5. By using (3) and (4), calculate the scores $S\left(r_{i}\right)(i=$ $1,2, \ldots, m)$ and the accuracies $H\left(r_{i}\right)(i=1,2, \ldots, m)$ of all the overall values $r_{i}(i=1,2, \ldots, m)$.

Step 6. Rank the alternatives $A_{i}(i=1,2, \ldots, m)$ and then select the best one.

\section{Illustrative Example and Discussion}

In this section, we discuss a group of decision making problems in the logistics supply chain environment, which are concerned with a $4 \mathrm{PL}$ solution provider searching the best 3PL supplier for service value cocreation with its customer (an international manufacturing company group). Now suppose that there are five global 3PL suppliers $x_{i}(i=$ $1,2,3,4,5)$ and three decision makers (whose weighting vector $\left.u=(0.4,0.25,0.35)^{T}\right)$ from different professional fields are involved in the decision making. In the following, we utilize the procedure to find the decision result.

Step 1. Determine the attributes for 3PL supplier selection in service value cocreation environment. The attributes which are considered here in selection for the best 3PL supplier are as follows; (1) $P_{1}$ is value collaboration ability with each other; (2) $P_{2}$ is knowledge matching ability; (3) $P_{3}$ is service innovation ability; (4) $P_{4}$ is quality of service; (5) $P_{5}$ is resource interaction ability.

Step 2. Utilize the weighting vector $\omega=(0.2,0.15,0.15,0.3$, $0.2)^{T}$ for 3PL supplier selection attributes and utilize the intuitionistic fuzzy decision matrix $R^{(k)}=\left(r_{i j}^{(k)}\right)_{m \times n}(k=$ $1,2,3,4)$ as listed in Tables 2-4.

Step 3. Give the associated vector $w=(0.3,0.45,0.25)^{T}$ of the I-IFEHA ${ }_{w, \omega}$ operator. Then we utilize the I-IFEHA $w, \omega$ operator to aggregate all the intuitionistic fuzzy decision matrices into a collective decision matrix $R=\left(r_{i j}\right)_{m \times n}$ (as listed in Table 5). 
TABLE 2: Intuitionistic fuzzy decision matrix $R^{(1)}$.

\begin{tabular}{cccccc}
\hline & $P_{1}$ & $P_{2}$ & $P_{3}$ & $P_{4}$ & $P_{5}$ \\
\hline$x_{1}$ & $(0.7,0.1)$ & $(0.6,0.2)$ & $(0.9,0.1)$ & $(0.5,0.3)$ & $(0.8,0.1)$ \\
$x_{2}$ & $(0.8,0.1)$ & $(0.7,0.1)$ & $(0.6,0.3)$ & $(0.7,0.1)$ & $(0.8,0.1)$ \\
$x_{3}$ & $(0.9,0.1)$ & $(0.5,0.2)$ & $(0.7,0.1)$ & $(0.8,0.1)$ & $(0.7,0.2)$ \\
$x_{4}$ & $(0.7,0.2)$ & $(0.7,0.2)$ & $(0.5,0.3)$ & $(0.5,0.4)$ & $(0.6,0.3)$ \\
$x_{5}$ & $(0.8,0.1)$ & $(0.8,0.1)$ & $(0.7,0.1)$ & $(0.5,0.2)$ & $(0.5,0.4)$ \\
\hline
\end{tabular}

TABLE 3: Intuitionistic fuzzy decision matrix $R^{(2)}$.

\begin{tabular}{cccccc}
\hline & $P_{1}$ & $P_{2}$ & $P_{3}$ & $P_{4}$ & $P_{5}$ \\
\hline$x_{1}$ & $(0.9,0.1)$ & $(0.7,0.2)$ & $(0.5,0.3)$ & $(0.7,0.2)$ & $(0.7,0.1)$ \\
$x_{2}$ & $(0.7,0.2)$ & $(0.8,0.1)$ & $(0.5,0.4)$ & $(0.6,0.2)$ & $(0.8,0.1)$ \\
$x_{3}$ & $(0.8,0.1)$ & $(0.6,0.2)$ & $(0.7,0.1)$ & $(0.8,0.1)$ & $(0.6,0.2)$ \\
$x_{4}$ & $(0.6,0.3)$ & $(0.7,0.1)$ & $(0.6,0.3)$ & $(0.5,0.2)$ & $(0.7,0.2)$ \\
$x_{5}$ & $(0.8,0.2)$ & $(0.5,0.1)$ & $(0.8,0.1)$ & $(0.6,0.3)$ & $(0.5,0.2)$ \\
\hline
\end{tabular}

TABLE 4: Intuitionistic fuzzy decision matrix $R^{(3)}$.

\begin{tabular}{cccccc}
\hline & $P_{1}$ & $P_{2}$ & $P_{3}$ & $P_{4}$ & $P_{5}$ \\
\hline$x_{1}$ & $(0.6,0.3)$ & $(0.8,0.1)$ & $(0.8,0.1)$ & $(0.4,0.3)$ & $(0.7,0.2)$ \\
$x_{2}$ & $(0.8,0.2)$ & $(0.6,0.3)$ & $(0.5,0.3)$ & $(0.6,0.2)$ & $(0.6,0.2)$ \\
$x_{3}$ & $(0.6,0.3)$ & $(0.7,0.2)$ & $(0.6,0.2)$ & $(0.8,0.1)$ & $(0.8,0.1)$ \\
$x_{4}$ & $(0.6,0.2)$ & $(0.5,0.4)$ & $(0.7,0.1)$ & $(0.6,0.2)$ & $(0.6,0.3)$ \\
$x_{5}$ & $(0.7,0.2)$ & $(0.6,0.2)$ & $(0.8,0.1)$ & $(0.4,0.4)$ & $(0.6,0.3)$ \\
\hline
\end{tabular}

Step 4. Utilize the IFEWA operator to get the collective overall values $r_{i}(i=1,2,3,4,5)$ of the alternatives $x_{i}(i=$ $1,2,3,4,5)$ :

$$
\begin{aligned}
& r_{1}=(0.707,0.169), \\
& r_{2}=(0.691,0.167), \\
& r_{3}=(0.739,0.134), \\
& r_{4}=(0.605,0.233), \\
& r_{5}=(0.645,0.192) .
\end{aligned}
$$

Step 5. Calculate the scores $S\left(r_{i}\right)(i=1,2,3,4,5)$ of all the overall values $r_{i}(i=1,2,3,4,5)$ :

$$
\begin{aligned}
& S\left(r_{1}\right)=0.538, \\
& S\left(r_{2}\right)=0.524, \\
& S\left(r_{3}\right)=0.605, \\
& S\left(r_{4}\right)=0.372, \\
& S\left(r_{5}\right)=0.453 .
\end{aligned}
$$

Step 6. Rank all the alternatives $x_{i}(i=1,2,3,4,5)$ in accordance with the scores $S\left(r_{i}\right)(i=1,2,3,4,5)$; we get $x_{3}>x_{1}>x_{2}>x_{5}>x_{4}$, and thus the most desirable alternative 3PL provider is $x_{3}$.

Now, we use the I-IFHA operator and IFWA operator proposed in [45] to aggregate the individual intuitionistic fuzzy information into a collective one to select the suitable 3PL provider.

Step 1. Firstly, we utilize the I-IFHA operator to aggregate all the intuitionistic fuzzy decision matrices into a collective decision matrix $R^{\prime}=\left(r_{i j}^{\prime}\right)_{m \times n}($ as listed in Table 6).

Step 2. Utilize the IFWA operator to get the collective overall values $r_{i}^{\prime}(i=1,2,3,4,5)$ of the alternatives $x_{i}(i=$ $1,2,3,4,5)$ :

$$
\begin{aligned}
& r_{1}^{\prime}=(0.702,0.160), \\
& r_{2}^{\prime}=(0.694,0.160), \\
& r_{3}^{\prime}=(0.746,0.136), \\
& r_{4}^{\prime}=(0.605,0.239), \\
& r_{5}^{\prime}=(0.647,0.192) .
\end{aligned}
$$

Step 3. Calculate the scores $S\left(r_{i}^{\prime}\right)(i=1,2,3,4,5)$ of all the overall values $r_{i}^{\prime}(i=1,2,3,4,5)$ :

$$
\begin{aligned}
& S\left(r_{1}^{\prime}\right)=0.542, \\
& S\left(r_{2}^{\prime}\right)=0.534, \\
& S\left(r_{3}^{\prime}\right)=0.610, \\
& S\left(r_{4}^{\prime}\right)=0.366, \\
& S\left(r_{5}^{\prime}\right)=0.455 .
\end{aligned}
$$

Step 4. Rank all the alternatives $x_{i}(i=1,2,3,4,5)$ in accordance with the scores $S\left(r_{i}^{\prime}\right)(i=1,2,3,4,5)$; we get $x_{3}>x_{1}>x_{2}>x_{5}>x_{4}$, and thus the most desirable alternative 3PL provider is $x_{3}$.

We can see that the results of the two induced intuitionistic fuzzy hybrid aggregation operators based on either the algebraic operational laws of IFSs or the Einstein operational laws are the same. Therefore, the approach proposed in this paper is effective and valid. And we also can see that the overall values of $r_{i}(i=1,2,3,4,5)$ using I-IFEHA operator are smaller than that of $r_{i}^{\prime}(i=1,2,3,4,5)$ using the IIFHA operator with respect to the partial order, respectively. That is to say, the proposed I-IFEHA operator shows more pessimistic attitude of the decision makers than the I-IFHA operator in aggregation process, which reveals the same result of the operator pair of I-IFOWA and I-IFEOWA proposed by Xu et al. [44]. Therefore, the I-IFEHA operator is also an effective approach for decision making information aggregation.

\section{Conclusion}

In this paper, we investigate the supplier selection multiple attribute decision making problems with intuitionistic fuzzy numbers. Firstly, we introduced some operational laws 
TABLE 5: Intuitionistic fuzzy decision matrix $R$.

\begin{tabular}{lccccc}
\hline & $P_{1}$ & $P_{2}$ & $P_{3}$ & $P_{4}$ & $P_{5}$ \\
\hline$x_{1}$ & $(0.799,0.133)$ & $(0.703,0.169)$ & $(0.746,0.166)$ & $(0.579,0.251)$ & $(0.734,0.119)$ \\
$x_{2}$ & $(0.759,0.163)$ & $(0.730,0.133)$ & $(0.532,0.342)$ & $(0.632,0.163)$ & $(0.760,0.119)$ \\
$x_{3}$ & $(0.804,0.133)$ & $(0.600,0.200)$ & $(0.677,0.119)$ & $(0.800,0.100)$ & $(0.689,0.169)$ \\
$x_{4}$ & $(0.632,0.241)$ & $(0.657,0.177)$ & $(0.600,0.231)$ & $(0.527,0.248)$ & $(0.648,0.251)$ \\
$x_{5}$ & $(0.778,0.163)$ & $(0.635,0.119)$ & $(0.774,0.100)$ & $(0.525,0.287)$ & $(0.527,0.275)$ \\
\hline
\end{tabular}

TABLE 6: Intuitionistic fuzzy decision matrix $R^{\prime}$.

\begin{tabular}{lccccc}
\hline & $P_{1}$ & $P_{2}$ & $P_{3}$ & $P_{4}$ & $P_{5}$ \\
\hline$x_{1}$ & $(0.748,0.147)$ & $(0.708,0.157)$ & $(0.809,0.132)$ & $(0.531,0.271)$ & $(0.745,0.127)$ \\
$x_{2}$ & $(0.779,0.152)$ & $(0.700,0.147)$ & $(0.543,0.322)$ & $(0.644,0.152)$ & $(0.745,0.128)$ \\
$x_{3}$ & $(0.807,0.147)$ & $(0.605,0.200)$ & $(0.668,0.128)$ & $(0.800,0.100)$ & $(0.720,0.157)$ \\
$x_{4}$ & $(0.644,0.221)$ & $(0.641,0.214)$ & $(0.605,0.204)$ & $(0.538,0.264)$ & $(0.628,0.271)$ \\
$x_{5}$ & $(0.770,0.152)$ & $(0.680,0.128)$ & $(0.765,0.100)$ & $(0.496,0.282)$ & $(0.538,0.304)$ \\
\hline
\end{tabular}

and aggregation operators of IFVs; moreover, the paper introduces the Einstein product and Einstein sum which are good alternatives to the algebraic product and algebraic sum. Secondly, the paper developed the induced intuitionistic fuzzy Einstein hybrid aggregation operator and studied its desirable properties, such as commutativity, idempotency, boundedness, and monotonicity. By using the I-IFEHA, we are able to deal with complex decision making issues in which the given arguments are intuitionistic fuzzy values. Thirdly, we have also studied the supplier selection decision model for logistics service value cocreation; the evaluation attributes for supplier selection have extended from traditional quality of service to a complex evaluation indicator system, including value collaboration, knowledge matching, service innovation ability, quality of service, and resource interaction. We have also developed an approach to supplier selection group decision making in logistics service value cocreation with intuitionistic fuzzy information and I-IFEHA operator. Finally, an illustrative example in 3PL supplier selection domains is given to verify the developed approach and to demonstrate its practicality and effectiveness. In the future, we will continue working in the extension and application of the developed operator to other actual fields.

\section{Conflict of Interests}

The authors declare that there is no conflict of interests regarding the publication of this paper.

\section{Acknowledgments}

This paper is supported by the Research Project of Philosophy and Social Science of Zhejiang Province (no. 14NDJC239YB), Key Research Institute of Philosophy and Social Sciences of Zhejiang Province, Modern Port Service Industry and Creative Culture Research Center (no. 13JDLG03YB), and the Technology Innovation Team Project of Ningbo (no. 2012B82003).

\section{References}

[1] J. Y. Chai, J. N. K. Liu, and E. W. T. Ngai, "Application of decision-making techniques in supplier selection: a systematic review of literature," Expert Systems with Applications, vol. 40, no. 10, pp. 3872-3885, 2013.

[2] M. S. Spencer, D. S. Rogers, and P. J. Daugherty, "JIT systems and external logistics suppliers," International Journal of Operations and Production Management, vol. 14, no. 6, pp. 60-74, 1994.

[3] A. B. Maltz, "The relative importance of cost and quality in the outsourcing of warehousing," Journal of Business Logistics, vol. 15, no. 2, pp. 45-62, 1994.

[4] K.-H. Lai, E. W. T. Ngai, and T. C. E. Cheng, "Measures for evaluating supply chain performance in transport logistics," Transportation Research Part E: Logistics and Transportation Review, vol. 38, no. 6, pp. 439-456, 2002.

[5] D. Andersson and A. Norrman, "Procurement of logistics services-a minutes work or a multi-year project?" European Journal of Purchasing and Supply Management, vol. 8, no. 1, pp. 3-14, 2002.

[6] P. R. Murphy and J. M. Daley, "Investigating selection criteria for international freight forwarders," Transportation Journal, vol. 37, no. 1, pp. 29-36, 1997.

[7] A. Aguezzoul, "Third-party logistics selection problem: a literature review on criteria and methods," Omega, vol. 49, no. 1, pp. 69-78, 2014.

[8] W. Ho, X. Xu, and P. K. Dey, "Multi-criteria decision making approaches for supplier evaluation and selection: a literature review," European Journal of Operational Research, vol. 202, no. 1, pp. 16-24, 2010.

[9] K. Govindan, M. Palaniappan, Q. Zhu, and D. Kannan, "Analysis of third party reverse logistics provider using interpretive structural modeling," International Journal of Production Economics, vol. 140, no. 1, pp. 204-211, 2012.

[10] K.-H. Lai, "Service capability and performance of logistics service providers," Transportation Research Part E: Logistics and Transportation Review, vol. 40, no. 5, pp. 385-399, 2004.

[11] G. Zhou, H. Min, C. Xu, and Z. Cao, "Evaluating the comparative efficiency of Chinese third-party logistics providers using data envelopment analysis," International Journal of Physical 
Distribution and Logistics Management, vol. 38, no. 4, pp. 262279, 2008.

[12] A. Hamdan and K. J. Rogers, "Evaluating the efficiency of 3PL logistics operations," International Journal of Production Economics, vol. 113, no. 1, pp. 235-244, 2008.

[13] F. Li, L. Li, C. J. Jin, R. Wang, H. Wang, and L. Yang, "A 3PL supplier selection model based on fuzzy sets," Computers and Operations Research, vol. 39, no. 8, pp. 1879-1884, 2012.

[14] D. Falsini, F. Fondi, and M. M. Schiraldi, "A logistics provider evaluation and selection methodology based on AHP, DEA and linear programming integration," International Journal of Production Research, vol. 50, no. 17, pp. 4822-4829, 2012.

[15] W. Ho, T. He, C. K. M. Lee, and A. Emrouznejad, "Strategic logistics outsourcing: an integrated QFD and fuzzy AHP approach," Expert Systems with Applications, vol. 39, no. 12, pp. 10841-10850, 2012.

[16] S. Perçin and H. Min, "A hybrid quality function deployment and fuzzy decision-making methodology for the optimal selection of third-party logistics service providers," International Journal of Logistics Research and Applications, vol. 16, no. 5, pp. 380-397, 2013.

[17] K. T. Atanassov, "Intuitionistic fuzzy sets," Fuzzy Sets and Systems, vol. 20, no. 1, pp. 87-96, 1986.

[18] K. T. Atanassov, "More on intuitionistic fuzzy sets," Fuzzy Sets and Systems, vol. 33, no. 1, pp. 37-45, 1989.

[19] L. A. Zadeh, "Fuzzy sets," Information and Control, vol. 8, no. 3, pp. 338-353, 1965.

[20] X. F. Zhao and G. W. Wei, "Some intuitionistic fuzzy Einstein hybrid aggregation operators and their application to multiple attribute decision making," Knowledge-Based Systems, vol. 37, pp. 472-479, 2013.

[21] S.-M. Chen and J.-M. Tan, "Handling multicriteria fuzzy decision-making problems based on vague set theory," Fuzzy Sets and Systems, vol. 67, no. 2, pp. 163-172, 1994.

[22] D. H. Hong and C.-H. Choi, "Multi-criteria fuzzy decisionmaking problems based on vague set theory," Fuzzy Sets and Systems, vol. 114, no. 1, pp. 103-113, 2000.

[23] S. Z. Zeng, J. M. Merigó, and W. H. Su, "The uncertain probabilistic OWA distance operator and its application in group decision making," Applied Mathematical Modelling, vol. 37, no. 9, pp. 6266-6275, 2013.

[24] W. H. Su, W. Z. Peng, S. Z. Zeng, B. Peng, and T. J. Pan, “A method for fuzzy group decision making based on induced aggregation operators and Euclidean distance," International Transactions in Operational Research, vol. 20, no. 4, pp. 579-594, 2013.

[25] G. W. Wei and X. F. Zhao, "Induced hesitant interval-valued fuzzy Einstein aggregation operators and their application to multiple attribute decision making," Journal of Intelligent and Fuzzy Systems, vol. 24, no. 4, pp. 789-803, 2013.

[26] Y. Xu and H. Wang, "The induced generalized aggregation operators for intuitionistic fuzzy sets and their application in group decision making," Applied Soft Computing Journal, vol. 12, no. 3, pp. 1168-1179, 2012.

[27] Z. Yue, "A group decision making approach based on aggregating interval data into interval-valued intuitionistic fuzzy information," Applied Mathematical Modelling, vol. 38, no. 2, pp. 683-698, 2014.

[28] X. M. Zhang and Z. S. Xu, "A new method for ranking intuitionistic fuzzy values and its application in multi-attribute decision making," Fuzzy Optimization and Decision Making, vol. 11, no. 2, pp. 135-146, 2012.
[29] Z. M. Zhang, "Generalized Atanassov's intuitionistic fuzzy power geometric operators and their application to multiple attribute group decision making," Information Fusion, vol. 14, no. 4, pp. 460-486, 2013.

[30] J.-J. Peng, J.-Q. Wang, X.-H. Wu, H.-Y. Zhang, and X.-H. Chen, "The fuzzy cross-entropy for intuitionistic hesitant fuzzy sets and their application in multi-criteria decision-making," International Journal of Systems Science, vol. 46, no. 13, pp. 23352350, 2015.

[31] J.-Q. Wang, Z.-Q. Han, and H.-Y. Zhang, "Multi-criteria group decision-making method based on intuitionistic interval fuzzy information," Group Decision and Negotiation, vol. 23, no. 4, pp. 715-733, 2014.

[32] J. Q. Wang, P. Zhou, K. J. Li, H. Y. Zhang, and X. H. Chen, "Multi-criteria decision-making method based on normal intuitionistic fuzzy-induced generalized aggregation operator," TOP, vol. 22, no. 3, pp. 1103-1122, 2014.

[33] J.-Q. Wang, R. Nie, H.-Y. Zhang, and X.-H. Chen, "New operators on triangular intuitionistic fuzzy numbers and their applications in system fault analysis," Information Sciences, vol. 251, pp. 79-95, 2013.

[34] J.-Q. Wang, R.-R. Nie, H.-Y. Zhang, and X.-H. Chen, "Intuitionistic fuzzy multi-criteria decision-making method based on evidential reasoning," Applied Soft Computing Journal, vol. 13, no. 4, pp. 1823-1831, 2013.

[35] J.-Q. Wang and H.-Y. Zhang, "Multi-criteria decision-making approach based on Atanassov's intuitionistic fuzzy sets with incomplete certain information on weights," IEEE Transactions on Fuzzy Systems, vol. 21, no. 3, pp. 510-515, 2013.

[36] Z. Xu, "Intuitionistic fuzzy aggregation operators," IEEE Transactions on Fuzzy Systems, vol. 15, no. 6, pp. 1179-1187, 2007.

[37] Z.S. Xu and R. R. Yager, "Some geometric aggregation operators based on intuitionistic fuzzy sets," International Journal of General Systems, vol. 35, no. 4, pp. 417-433, 2006.

[38] J. M. Merigó, "A unified model between the weighted average and the induced OWA operator," Expert Systems with Applications, vol. 38, no. 9, pp. 11560-11572, 2011.

[39] G. W. Wei, "Some geometric aggregation functions and their application to dynamic multiple attribute decision making in the intuitionistic fuzzy setting," International Journal of Uncertainty, Fuzziness and Knowlege-Based Systems, vol. 17, no. 2, pp. 179-196, 2009.

[40] G. W. Wei, "Some induced geometric aggregation operators with intuitionistic fuzzy information and their application to group decision making," Applied Soft Computing Journal, vol. 10, no. 2, pp. 423-431, 2010.

[41] Y. J. Xu and H. M. Wang, “The induced generalized aggregation operators for intuitionistic fuzzy sets and their application in group decision making," Applied Soft Computing, vol. 12, no. 3, pp. 1168-1179, 2012.

[42] W. Z. Wang and X. W. Liu, "Intuitionistic fuzzy geometric aggregation operators based on einstein operations," International Journal of Intelligent Systems, vol. 26, no. 11, pp. 1049-1075, 2011.

[43] W. Z. Wang and X. W. Liu, "Intuitionistic fuzzy information aggregation using Einstein operations," IEEE Transactions on Fuzzy Systems, vol. 20, no. 5, pp. 923-938, 2012.

[44] Y. J. Xu, Y. Y. Li, and H. M. Wang, "The induced intuitionistic fuzzy Einstein aggregation and its application in group decision-making," Journal of Industrial and Production Engineering, vol. 30, no. 1, pp. 2-14, 2013. 
[45] Z.-X. Su, G.-P. Xia, and M.-Y. Chen, "Some induced intuitionistic fuzzy aggregation operators applied to multi-attribute group decision making," International Journal of General Systems, vol. 40, no. 8, pp. 805-835, 2011.

[46] S. L. Vargo, P. P. Maglio, and M. A. Akaka, "On value and value co-creation: a service systems and service logic perspective," European Management Journal, vol. 26, no. 3, pp. 145-152, 2008.

[47] A. Yazdanparast, I. Manuj, and S. M. Swartz, "Co-creating logistics value: a service-dominant logic perspective," The International Journal of Logistics Management, vol. 21, no. 3, pp. 375403, 2010. 


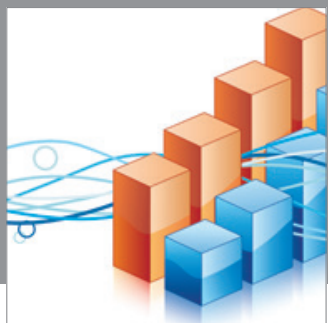

Advances in

Operations Research

mansans

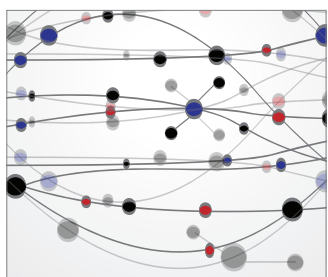

The Scientific World Journal
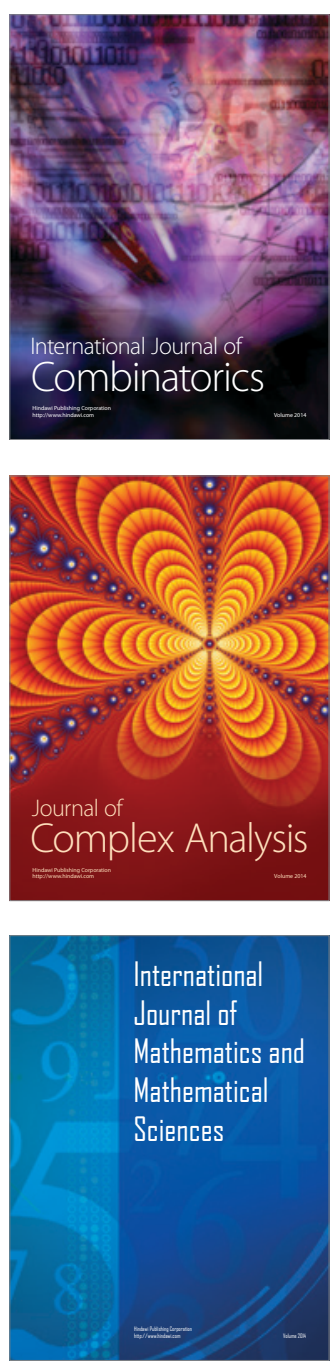
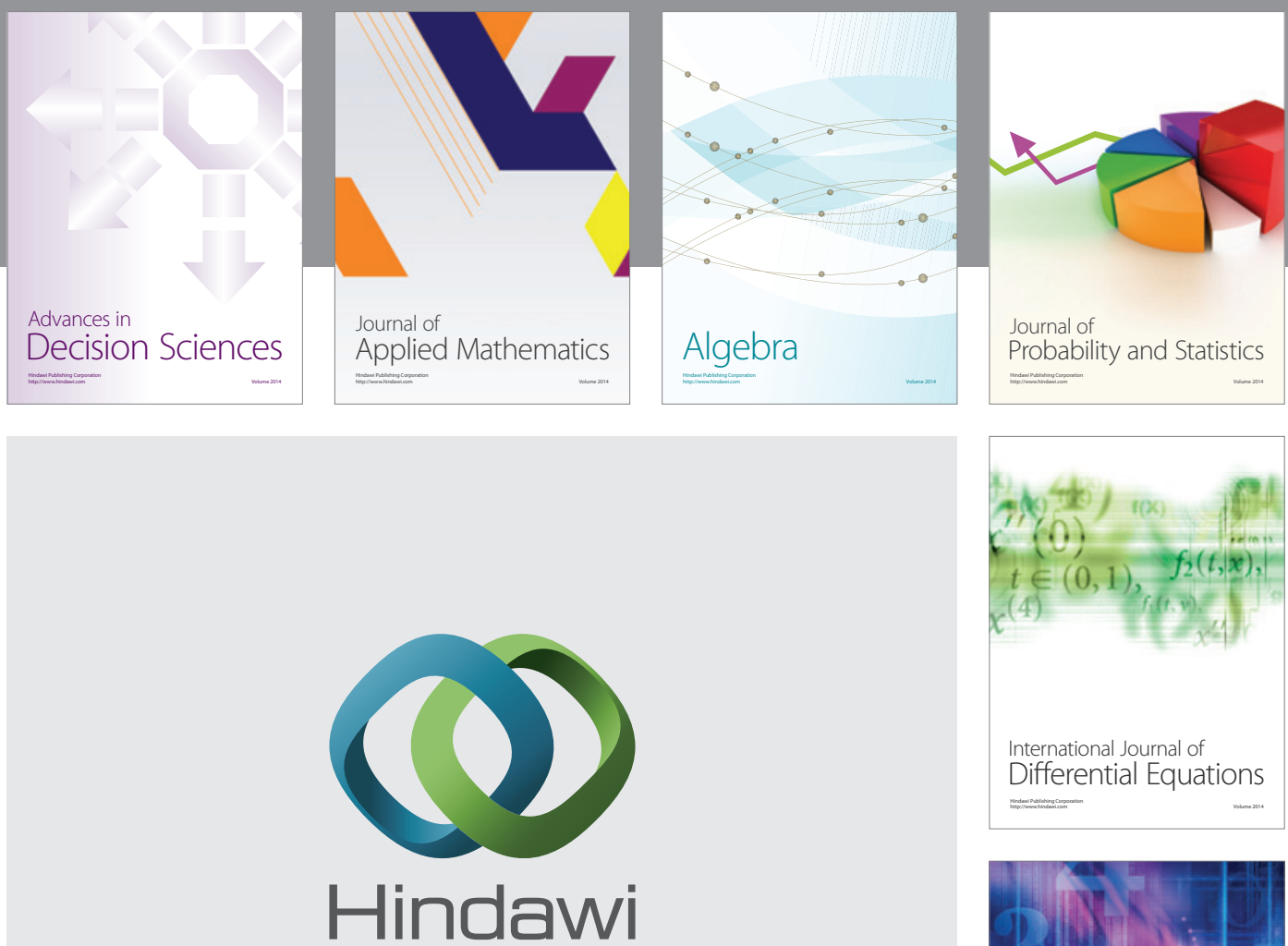

Submit your manuscripts at http://www.hindawi.com
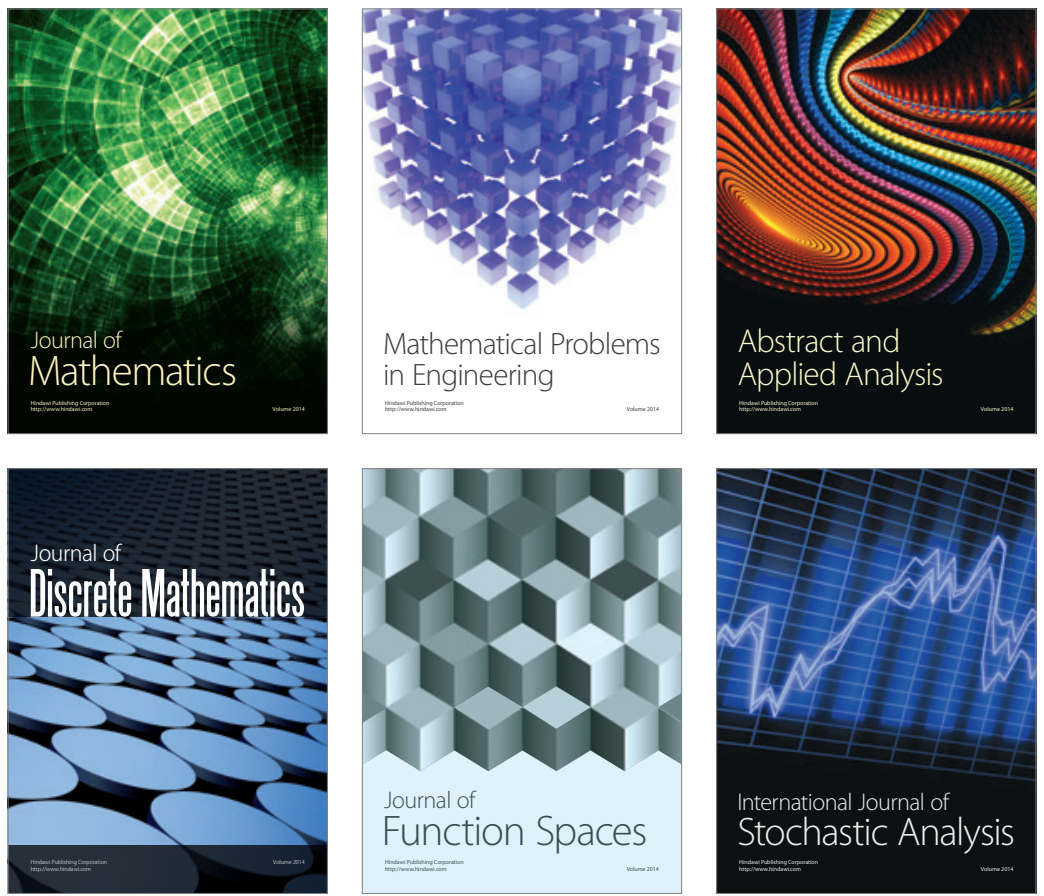

Journal of

Function Spaces

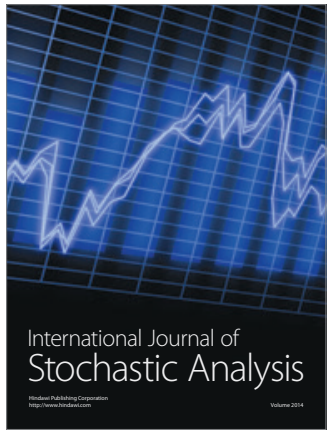

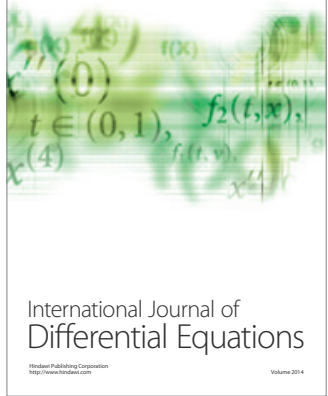
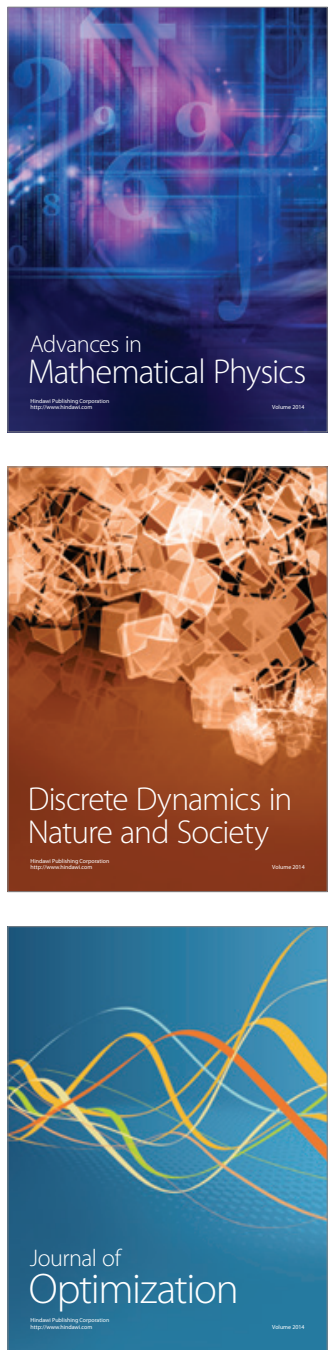